\title{
The Theory Of Planned Behavior: An Examination Of Governmental Financial Managers' Intentions To Modify Internal Controls For E-Services
}

\author{
Dwayne N. McSwain, (Email: dmcswain@mtsu.edu), Middle Tennessee State University \\ Sid Glandon, (Email: sglandon@utep.edu), University of Texas at El Paso \\ Terry Ann Glandon, (Email: tglandon@utep.edu), University of Texas at El Paso
}

\begin{abstract}
This study uses Ajzen's (1991) Theory of Planned Behavior as a theoretical framework to examine state and local government (SLG) financial managers' intentions to modify internal controls when implementing e-services. The primary objective of this study is to determine whether SLG financial managers' decision (intention) to support modification of internal controls is a function of his/her beliefs toward proper accounting internal controls. Results indicate significant support for a decision process based on attitude, subjective norm, and perceived behavioral control for modifying internal controls after adopting e-services. A priori, one would expect changes in business processes to lead to appropriate changes in internal controls; however, the mean response for intention in this study indicates only a mild propensity to make such changes. The data in this study suggest that financial managers of state and local governments are aware of their responsibilities for maintaining appropriate internal controls but express only slight interest in, willingness to, or belief they are able to modify internal controls to address the changes in accounting systems as a result of the adoption of e-services. Implications of electing to forego internal control modifications after business process changes are provided, along with suggestions for future research.
\end{abstract}

\section{INTRODUCTION}

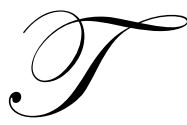

he recent scandals that rocked private-sector accounting (WorldCom, Enron, Adelphia, etc.) have heightened public awareness of the need for proper internal controls. Such events have not gone unnoticed in the public sector; the Government Finance Officers Association (GFOA) has asserted that government financial managers have an ethical and affirmative obligation to maintain proper internal controls (Gauthier 2006). Wallace (2004) claims that absent or weak internal controls increase the cost of public services and that all stakeholders (taxpayers, investors, auditors, regulators, elected and appointed officials, oversight bodies, etc.) should be concerned.

Internal control over information systems has become a crucial topic over the past five years, due in large part to the Sarbanes-Oxley Act of 2002 (SOX). This legislation may have precipitated the many studies (cf. Ashbaugh-Skaife et al. 2006a, Ashbaugh-Skaife et al. 2006b, Beneish et al. 2006, Bryan and Lilien 2005, Ge and McVay 2005, and Krishnan and Visvanathan 2005, among others) that examine internal controls in publicly held companies; however, little, if any, research has been conducted on the impact of technology and internal controls in government. Considering the magnitude of the impact of state and local government (SLG) operations on the U.S. economy - more than 17 million jobs and over \$1.5 trillion in annual spending (Freeman et al. 2006) - there is a need for more research in this area. 
The purpose of this study is to investigate the intentions of governmental financial managers to modify internal controls after implementing e-services. The primary objective of this research is to determine whether SLG financial managers' decision (intention) to support modification of internal controls is a function of his/her beliefs about proper accounting internal controls.

Ajzen's (1991) Theory of Planned Behavior (TPB) is used as a theoretical framework to examine SLG financial managers' intentions to adopt changes in internal controls. To obtain the data needed to examine this research issue, we conducted a multiphase study involving financial managers from all levels of state and local governmental entities. The first phase involved an elicitation survey to determine the outcome beliefs that underlie SLG financial managers' attitudes, subjective norms, and perceived behavioral controls. These beliefs were then integrated into the measures used in our survey instrument. A pilot study was conducted in the second phase. In the third phase, changes from the pilot test were incorporated into the final instrument and the survey was conducted.

The results of this study provide strong evidence for a decision process based on attitude, subjective norm, and perceived behavioral control regarding the adoption of internal control changes. In general, financial managers had overall intentions of modifying internal controls after implementing e-services, although their commitment was not especially strong. It is surprising that the control beliefs were not correlated with the direct measure of perceived behavioral control and were not in the expected direction. One explanation for this phenomenon may be that people sometimes demonstrate a relatively automatic reaction to global measures, but further analysis of the problem evokes a more reasoned action (Ajzen 1991).

The remainder of this paper is organized into four sections. The next section presents the related literature on the Theory of Planned Behavior along with the hypotheses. Next, the research design and methodology are discussed, followed by a summary of the results. This paper concludes with a summary discussion of the findings, the limitations of this study, and suggestions for future research.

\section{PRIOR RESEARCH AND THEORY}

Ajzen's (1991) Theory of Planned Behavior has been successfully tested across many disciplines in research on such topics as predicting new business ventures (Krueger and Carsrud 1993), benchmarking (Hill et al. 1996), adoption of information technology in small businesses (Harrison et al. 1997), college student achievement (Manstead and van Eekelen 1998), and taxpayer compliance (Bobek and Hatfield 2003). The validity of this theory across multiple settings suggests that it may be appropriate in the matter of SLG financial managers' decision to change internal controls.

According to the theory, individuals are motivated by certain factors to perform a specific behavior. ${ }^{1}$ Ajzen posits that behavioral intentions are a positive function of one's attitude, subjective norms, and perceived behavioral control. The definition of attitude is the individual's positive/negative evaluation of performing the behavior; subjective norm is the individual's perception of social pressures to perform or not perform the behavior; and perceived behavioral control is the individual's assessment of the ease or difficulty of performing the behavior. ${ }^{2}$

\section{Intention} control.

Figure 1 illustrates the relationship among intention, attitude, subjective norm and perceived behavioral

\footnotetext{
${ }^{1}$ The study measured behavioral intentions, not actual behavior. Ajzen (1991) argues that a wealth of research has shown intentions are highly correlated with actual behavior, so measuring actual behavior is not necessary. Because we had promised anonymity to the financial managers who agreed to complete the survey, we were unable to collect personal information in order to be able to contact them later to ascertain whether they had indeed modified internal controls.

${ }^{2}$ Actual behavioral control has not yet been defined or assessed at a global level, so the individual's perception of the control he or she has over events is used in its place (Ajzen 1985).
} 
Mathematically, the Theory of Planned Behavior can be stated as follows:

Intention $=w_{l}\left(\mathrm{~A}_{B}\right)+w_{2}\left(\mathrm{SN}_{B}\right)+w_{3}\left(\mathrm{PBC}_{B}\right)$

Where

$\mathrm{A}=\quad$ Attitude

$\mathrm{SN}=\quad$ Subjective Norm

$\mathrm{PBC}=$ Perceived Behavioral Control

$w_{i}=\quad$ weights that vary across people and contexts

${ }_{B}=$ the behavior

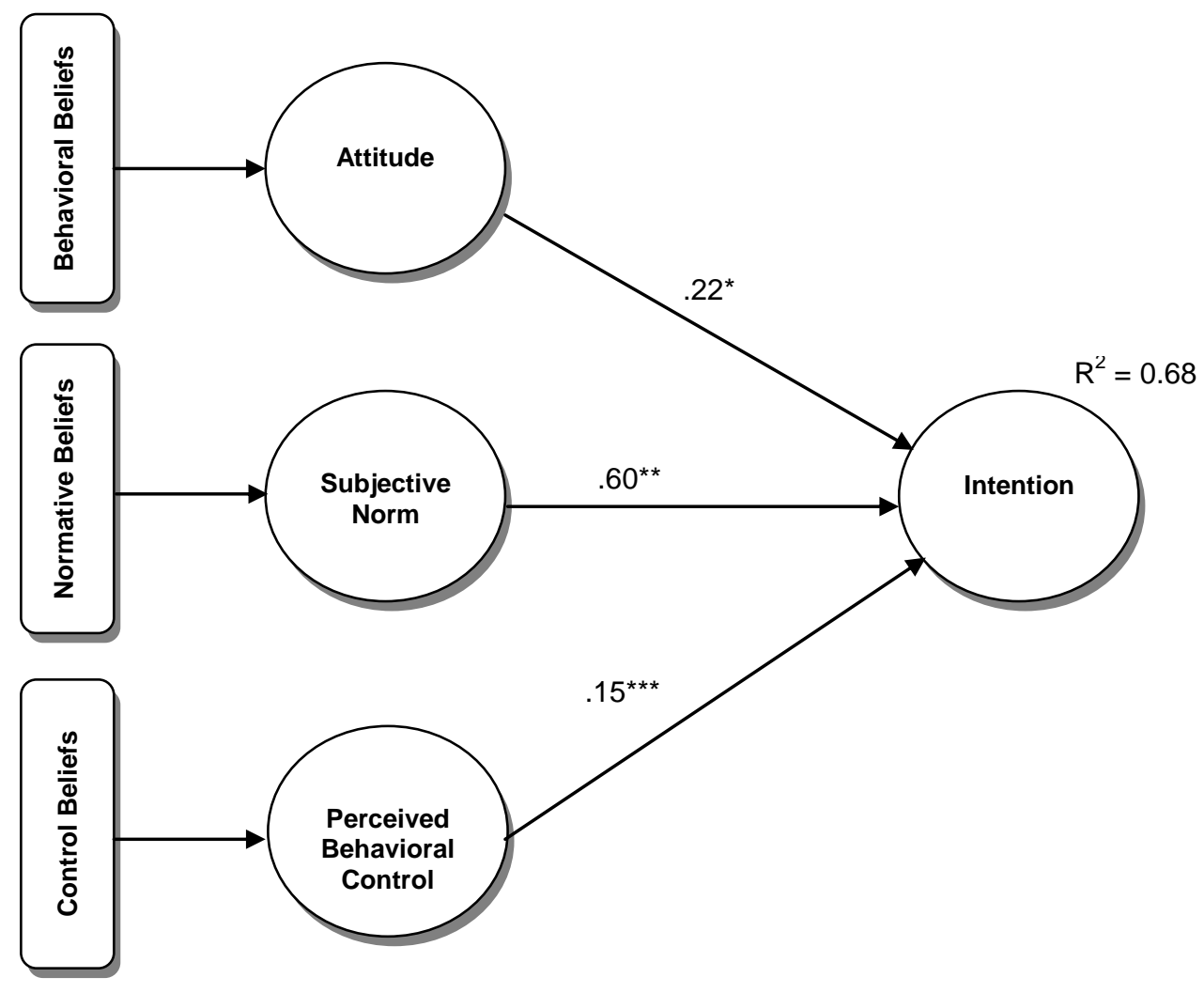

* $p=0.009$

** $p<0.001$

*** $p=0.069$

Figure 1

\section{Attitude}

Attitude consists of behavioral beliefs, including perceived consequences and evaluation of the behavior. To estimate the individual's attitude toward a behavior, the subjective probability (or belief) that performing the behavior will result in a particular outcome is multiplied by the evaluation of that outcome and summed over $i$ behavioral beliefs, as shown in equation 2 . 


$$
A_{B}=\sum_{i=1}^{I} b b_{i} e v_{i}
$$

In the current study, the consequences of modifying internal controls could be improved accuracy of the accounting records, decreased opportunity for fraud, or improved efficiency in daily operations. The financial manager's attitude toward changing internal controls is likely to be influenced by his or her positive (or negative) evaluation of those consequences.

\section{Subjective Norm}

Subjective norm consists of two constructs: influential others (or social referents) and the degree of motivation the individual possesses to comply with those individuals or groups. For an estimate of subjective norm, equation 3 shows that the normative belief is multiplied by the motivation to comply with the salient social referent and then summed over $j$ normative beliefs.

$$
S N_{B}=\sum_{j=1}^{J} n b_{j} m c_{j}
$$

Employees, accountants/auditors, department managers, and suppliers are among the social referents in the current research who may affect the financial manager's decision. If the manager is strongly motivated to comply with his or her social referents, the effect on subjective norm could be substantial.

\section{Perceived Behavioral Control}

The beliefs underlying perceived behavioral control are control beliefs that represent one's perception of available resources, opportunities, or potential barriers to accomplishing the behavior. To estimate perceived behavioral control, each control belief is multiplied by the perceived power to facilitate (or obstruct) the performance of the behavior and summed over $k$ control beliefs. This formula is depicted in equation 4 .

$$
P B C_{B}=\sum_{k=1}^{K} c b_{k} p p_{k}
$$

Examples of some of the control beliefs from the initial elicitation study are budget limitations, additional training for employees, and employee resistance to change. Each control belief (obstacle) is multiplied by the financial manager's perceived power (assessment of the importance) to overcome the obstacle in the decision to change internal controls.

\section{Optimal Rescaling}

Ajzen (1991) proposes that bipolar scaling $(-3$ to +3$)$ is appropriate for belief strengths as well as for evaluation of those beliefs. Therefore, the underlying beliefs for attitude (behavioral beliefs and evaluations) were scored with a bipolar scale, as were the underlying beliefs for perceived behavioral control (control beliefs and perceived power). For subjective norm, however, normative beliefs were scored using the bipolar scale, and a unipolar scale (1 to 7) was used for the motivation to comply with the social referent because people are unlikely to be motivated to do the opposite of what their salient referents think they should do (Ajzen and Fishbein 1980). 


\section{Hypotheses}

The above discussion provides the basis for using the direct determinants in the Theory of Planned Behavior to research intentions of state and local government financial managers to change internal controls after implementing e-services. The following hypotheses are stated in the alternative form:

H1: A financial manager's intention to modify internal controls is a function of the manager's attitude toward changing internal controls.

H2: A financial manager's intention to modify internal controls is a function of the manager's subjective norm regarding changing internal controls.

H3: A financial manager's intention to modify internal controls is a function of the manager's perceived behavioral control over changing internal controls.

\section{METHODOLOGY}

\section{Identification and Selection of Target Population}

Our target population was financial managers of state and local governments (SLGs) located within the United States who use some form of e-services. The list of managers came from the 2002 Census of Governments (U.S. Census Bureau 2002), which reports that almost 25,000 (24,878) governmental entities have the capability to communicate or transact business with the public via the Internet, e-mail, or other electronic means. Information for the primary governmental entity of each state and the District of Columbia was added to the Census report, resulting in a total target population of 24,929 state and local governmental entities, as presented in Table 1.

Table 1

Target Population

\begin{tabular}{cccccc}
\hline $\begin{array}{c}\text { Type of Governmental } \\
\text { Entity }\end{array}$ & \multicolumn{2}{c}{ eGovernment $^{\text {a }}$} & \multicolumn{2}{c}{$\begin{array}{c}\text { Primary } \\
\text { Governments }\end{array}$} & \multicolumn{2}{c}{ Target Population } \\
\hline State & Count & Percent & Count & Count & Percent \\
County & 64 & 0.25 & 51 & 115 & 0.46 \\
Municipality & 1,530 & 6.15 & & 1,530 & 6.14 \\
Township & 5,945 & 23.90 & & 5,945 & 23.85 \\
Special District & 2,385 & 9.59 & & 2,385 & 9.57 \\
School District & 7,013 & 28.19 & $\underline{719}$ & $\underline{7,013}$ & 28.13 \\
Totals & $\underline{7,941}$ & $\underline{31.92}$ & $\underline{00}$ & $\underline{24,929}$ & $\underline{100.00}$ \\
\hline
\end{tabular}

${ }^{a}$ Source: 2002 Census of Governments, respondents reporting that the "public can communicate or transact business via [the] Internet, e-mail or other electronic means," U.S. Census Bureau.

b The primary governments of the 50 states and the District of Columbia, not included in the 2002 Census of Governments, were added to the target population.

There are substantially fewer primary state governmental entities than any other type —only 51 (50 states plus the District of Columbia) out of almost 25,000. To ensure that a sufficient number of state governments would be included in the final sample, we used disproportionate stratified sampling. This method results in heterogeneous levels of various governmental entities, including the relatively small percentage of primary state governments (Joppe 2004). "Type of governmental entity" served as the strata and 100 governmental entities were randomly selected from each stratum, resulting in a final sample size of 600. A detailed discussion of the sampling procedure used is delineated in the sample selection and descriptive data section below. 


\section{Elicitation Study}

Ajzen and Fishbein (1980) suggest administering an open-ended elicitation questionnaire to a small sample (about 20) of the target population to determine salient consequences (attitude), referents (subjective norm), and resources or obstacles (perceived behavioral control). They encourage using specific terminology, such as "advantages" and "disadvantages" when referring to salient consequences and "individuals who would approve or disapprove of the behavior" for salient referents. "Potential obstacles" can represent facts or circumstances that might prevent the action from being completed.

We asked 22 financial managers who were personally acquainted with at least one of the researchers to list (1) advantages and disadvantages of changing internal controls; (2) individuals, groups or organizations that might approve or disapprove of the internal controls being modified; and (3) potential obstacles that might prevent changing internal controls. Responses to this elicitation survey were categorized and rank-ordered separately by two researchers. The researchers compared answers and reached an agreement on those to be retained. The responses listed most frequently were included in the final questionnaire for measures of behavioral beliefs and evaluations of those beliefs; normative beliefs and related motivations to comply; and control beliefs and perceived power. ${ }^{3}$ Direct measures of behavioral intention, attitude, subjective norm, and perceived behavioral control were added to the final survey instrument, along with questions to collect demographic data on the respondents.

\section{Pilot Test}

Eight governmental managers and two faculty members pilot-tested the survey. Each participant was contacted by one of the researchers and asked to complete either the paper survey or the Web survey. Four participants completed the paper survey, and the other four completed the Web version. Based on participants' feedback, two questions perceived as duplicates were removed, and another was reworded for clarity. These changes were incorporated into the final version, which is presented in the appendix.

\section{Final Survey}

Paper surveys, cover letters, and return envelopes were mailed to 600 financial managers of governmental entities. The cover letter also included the website address to allow the respondent to complete the survey online. The participants were told their responses would be anonymous; however, they could include a business card when returning the survey instrument if they wished to receive a summary of the research results.

Because the survey form did not ask for any information about the individual respondent or the governmental entity, we were unable to track those who had (or had not) returned the surveys. In the hope of obtaining a higher response rate there is a tradeoff between conducting an anonymous survey and the resulting inability to retain records of responders versus nonresponders. Reminder postcards were sent to the entire sample two weeks after the initial mailing.

\section{Instrument Validity}

Internal consistency of the questionnaire items for each construct was tested, resulting in the measure of Cronbach's alpha. This technique focuses on the degree to which the same characteristic is being measured. For the current study, the reliability estimates (alpha) for each of the direct measures are as follows: behavioral intention $(\mathrm{r}=$ $0.85)$, attitude $(\mathrm{r}=0.95)$, subjective norm $(\mathrm{r}=0.70)$ and perceived behavioral control $(\mathrm{r}=0.82)$. All of these values, as shown in Table 2, are at or above the recommended levels of 0.70 . Reliability estimates of the underlying beliefs (behavioral, normative and control beliefs) were not calculated. Ajzen and Fishbein (1980) advise against analyzing these items because it is logical to assume that individuals will possess conflicting (positive and negative) beliefs

\footnotetext{
${ }^{3}$ Frequency is recognized as an indicator of importance: the more a phenomenon occurs, the more likely it is nonrandom and thus important (Lacity and Janson 1994).
} 
about the particular characteristics of multifaceted decisions. Therefore, internal consistency estimates for the underlying beliefs would not be meaningful because estimates such as Cronbach's alpha assume a uniform construct that is not multi-dimensional.

Table 2

Instrument Reliabilities (Cronbach's Alpha)

\begin{tabular}{cc}
\hline Measure & $\boldsymbol{\alpha}$ \\
\hline Behavioral Intention & 0.85 \\
Attitude & 0.95 \\
Subjective Norm & 0.70 \\
Perceived Behavioral Control & 0.82 \\
\hline
\end{tabular}

\section{Content Validity}

Evaluating content validity is an important part of survey instrument validity. Eliciting responses from a small group of SLG financial managers to determine factors they consider obstacles, advantages, disadvantages, and social referents leads to strong content validity. Their responses provided questionnaire items regarding the underlying beliefs of attitude, subjective norm, and perceived behavioral control for the final survey instrument.

\section{Construct Validity}

Factor analysis was used to verify the instrument's factorial validity and ensure that theoretical constructs were distinct from each other, containing divergent validity (Cronbach, as cited in Harrison et al. 1997). An iterated principal axes analysis with a promax rotation was used to examine the underlying behavioral, normative, and control beliefs. An oblique rotation was used because it was likely the factors were correlated (Ajzen 1991). Three factors emerged, each pertaining to a separate construct of the Theory of Planned Behavior, lending support to the validity of this portion of the instrument and its theoretical underpinnings. Table 3 presents the loadings for these three factors, demonstrating that in their own perceptions, financial managers distinguish between behavioral beliefs, normative beliefs, and control beliefs.

Table 3

Rotated Factor Pattern Matrix of Behavioral, Normative, and Control Beliefs

\begin{tabular}{|c|c|c|c|c|}
\hline Belief & Item & Factor 1 & Factor 2 & Factor 3 \\
\hline \multirow[t]{6}{*}{ Behavioral } & Accuracy of the accounting records & 0.78 & & \\
\hline & More efficient daily operations & 0.89 & & \\
\hline & Decreased fraud or errors & 0.77 & & \\
\hline & Reduced accounting costs & 0.82 & & \\
\hline & Fewer personnel required & 0.70 & & \\
\hline & More reliable financial information & 0.82 & & \\
\hline \multirow[t]{4}{*}{ Normative } & Employees & & 0.92 & \\
\hline & Accountants or auditors & & 0.94 & \\
\hline & Suppliers & & 0.80 & \\
\hline & Department managers & & 0.74 & \\
\hline \multirow[t]{5}{*}{ Control } & Budget limitations & & & 0.75 \\
\hline & Employee resistance to change & & & 0.72 \\
\hline & Unfamiliarity with new controls & & & 0.86 \\
\hline & Sufficient time to implement new controls & & & 0.83 \\
\hline & Additional employee training & & & 0.57 \\
\hline
\end{tabular}




\section{Sample Section and Descriptive Data}

Six hundred surveys with cover letters were mailed to financial managers of governmental entities, and reminder postcards were sent to the entire sample two weeks after the initial mailing. Nine addresses were incorrect with no forwarding information available, resulting in a total of 591 surveys assumed to have reached their destination.

The respondents were given a choice between completing a paper survey and returning it in a postage-paid, self-addressed envelope or completing the survey online. Forty-eight returned the paper survey, and 59 completed it online, resulting in a total of 107 questionnaires returned, or a response rate of 18 percent (107/591). The majority of respondents were male (54 percent), were between the ages of 46 and 55, and with an average of 12.7 years of experience. Table 4 presents the demographic information about the participants.

Table 4

Participant Demographics

\begin{tabular}{cc}
\hline & Participants \\
\hline Age & $25 \%$ \\
$36-45$ & $46 \%$ \\
$46-55$ & $29 \%$ \\
$56-65$ & \\
Gender & $54 \%$ \\
Males & $46 \%$ \\
Females & \\
Experience & 1 year \\
Minimum & 34 years \\
Maximum & 12.7 years \\
Average & \\
\hline
\end{tabular}

Of the initial 107 financial managers who returned questionnaires, a subset could not be used for testing our hypotheses. Seven financial managers reported internal controls had already been modified. Because intention deals with future events, "intention to change controls" would not be meaningful and these seven agencies were omitted from the tests of the hypotheses.

Included in the cover letter was a paragraph asking that “... the person who completes the form have some responsibility regarding the agency's internal control procedures. If you feel some other person in the organization should complete the survey, we ask that you pass this letter and survey on to him or her." Nevertheless, eight managers completed the survey and indicated they had no influence ( 0 percent) on their agency's decision whether to modify internal controls. These respondents were excluded from further analyses; it is not likely their answers would accurately portray the agency's decision process.

Of the remaining respondents, the average reported influence was 57 percent, with 37 percent of the managers reporting they were the primary decision maker (i.e., having a greater than 50 percent influence on the decision). To confirm the applicability of the Theory of Planned Behavior in the current study's context, the percent of influence data was entered as a moderator in the regression equations to determine whether the empirical fit of the theory was significantly better (or worse) for those financial managers reporting stronger (or weaker) influence on the decision (Harrison et al. 1997). No significant effects emerged, implying a reasonably similar fit across the entire retained sample. 
The final sample consisted of 92 agencies (107 initial responses, less seven who had already made control changes, less eight not involved in the decision process) that were included in each of the tests of hypotheses discussed below.

\section{Regression and Correlation Analyses}

The hypotheses were tested using multiple linear regression, as suggested by Ajzen (1991). Although some researchers prefer structural equation modeling (e.g., Gillett and Uddin 2005, and others), both methods have advantages. Using multiple regression allows the standardized coefficients to serve as estimates of the weights for the theory's constructs (Ajzen and Fishbein 1980). ${ }^{4}$ Residual diagnostics were analyzed for lack of fit and for departures from assumptions of normality, equal variance, independence, and linearity. No significant violations were present.

Table 5 presents the correlation matrix between intention and each of the direct measures, and between the direct measures and their underlying beliefs. This schedule shows moderate to strong correlations between intention and attitude $(\mathrm{r}=.54)$, subjective norm $(\mathrm{r}=.73)$, and perceived behavioral control $(\mathrm{r}=.50)$. The correlation between attitude and its underlying behavioral beliefs $(\mathrm{r}=.47)$ and subjective norm and its underlying normative beliefs $(\mathrm{r}=$ $.50)$ are both moderate.

Table 5

Correlation Matrix

\begin{tabular}{|c|c|c|c|c|}
\hline Variable & BI & ATT & SN & PBC \\
\hline Behavioral Intention (BI) & 1.00 & & & \\
\hline Attitude (ATT) & 0.54 & 1.00 & & \\
\hline Subjective Norm $(\mathrm{SN})$ & 0.73 & 0.62 & 1.00 & \\
\hline Perceived Behavioral Control (PBC) & 0.50 & 0.42 & 0.54 & 1.00 \\
\hline Behavioral Beliefs & & 0.47 & & \\
\hline Normative Beliefs & & & 0.51 & \\
\hline Control Beliefs & & & & $\mathrm{n} / \mathrm{s}$ \\
\hline $\begin{array}{l}\mathrm{n}=92 \\
\text { Correlations are significant at } \mathrm{p}<0.0001 \text {, with the exc }\end{array}$ & ntrol & & & \\
\hline
\end{tabular}

\section{Results of Hypotheses Tests}

Hypothesis 1 predicted that a SLG financial manager's decision (intention) to modify internal controls after implementation of e-services is a function of his or her attitude toward internal controls. The impact of attitude was found to be significant at $p=0.009$, in which the result was $b=0.22$. These results suggest that managers value efficiency and reliability in the processing and presentation of financial information. Referring to table 6 , the most important issues of attitude are accuracy in accounting records (mean $=2.19)$, likelihood of decreased fraud and errors (2.15), efficiency in daily operations (1.90), and reliable financial information (1.60). Less importance was placed on reducing accounting costs $(0.85)$ and reducing personnel $(0.46)$.

Hypothesis 2 predicted that the influence of social referents, such as employees, auditors, and others, may affect the financial manager's decision (intention) to modify internal controls. This influence of social referents was significant at $p<0.0001$, where $b=0.60$. It was noted previously that the motivation to comply was scored from 1 to 7 (all other survey responses were scored from -3 to +3 ). Scores from the underlying components of subjective norm could range from $-3(-3 \times 1)$ to $21(+3 \times 7)$. As presented in table 6 , auditors and accountants had substantially greater influence on the manager's decision than the other social referents, with a mean of 8.65. Department managers followed, with a mean of 3.07. Of less importance was the influence of the suppliers (2.65) and employees (2.40).

\footnotetext{
${ }^{4}$ A structural equation model was also used to test the hypotheses, with similar results as the multiple regression model.
} 
Table 6

Means of Behavioral and Normative Beliefs

\begin{tabular}{cc}
\hline Behavioral Beliefs & Means \\
\hline Accuracy of the accounting records & 2.19 \\
Decreased fraud or errors & 2.15 \\
More efficient daily operations & 1.90 \\
More reliable financial information & 1.60 \\
Reduced accounting costs & 0.85 \\
Fewer personnel required & 0.46 \\
\hline Normative Beliefs & Means \\
\hline Accountants or auditors & 8.65 \\
Department managers & 3.07 \\
Suppliers & 2.65 \\
Employees & 2.40
\end{tabular}

Finally, Hypothesis 3 predicted that a financial manager's decision (intention) to modify controls is a function of the manager's perceived behavioral control over changing internal controls. The financial managers' perceived controls were found to be significant at $p=0.069$, where $b=0.15$. Due to the lack of a significant correlation between the direct measure of perceived behavioral control and its underlying beliefs, we do not provide further analysis on this construct. Ajzen (1991) proposes that responses to specific belief and valuation items may require more deliberations than responses to overall global measures; therefore, the global measures may evoke a relatively automatic reaction whereas the belief-related items evoke a relatively reasoned response.

Ajzen (1991) suggests that "the relative importance of attitude, subjective norm, and perceived behavioral control is expected to vary across behaviors and situations." As shown in table 7, subjective norm is the strongest direct measure $(b=0.60)$, yet the mean of 1.26 indicates that the managers' social referents are only slightly likely to approve of changing controls. The managers appear to positively view modification of controls after e-services implementation, with a mean of $1.51(b=0.22)$ for the direct measure of attitude. Finally, the direct measure of perceived behavioral control had the least impact on the managers' decisions with a mean of $1.05(b=0.15)$. The three constructs together explained a substantial portion of the variance in intentions $\left(R^{2}=0.68\right)$.

Table 7

Analysis of Predictors of Behavioral Intentions

\begin{tabular}{|c|c|c|c|c|c|}
\hline Variable & Mean & $b^{a}$ & $t$ & $p$ & $\begin{array}{c}\text { Change in } \\
\text { R-sq }^{\mathrm{b}}\end{array}$ \\
\hline Attitude (ATT) & 1.51 & 0.22 & 2.68 & 0.009 & 0.430 \\
\hline Subjective Norm (SN) & 1.26 & 0.60 & 6.98 & $<0.001$ & 0.242 \\
\hline Perceived behavioral control (PBC) & 1.05 & 0.15 & 1.84 & 0.069 & 0.008 \\
\hline $\begin{array}{l}\mathrm{n}=92 \\
\mathrm{a} \text { standardized estimates } \\
\mathrm{b} \text { at successive stages of the modelin } \\
\text { Adjusted } \mathrm{R}^{2}=0.68\end{array}$ & & & & & \\
\hline
\end{tabular}

\section{CONCLUSIONS, LIMITATIONS, AND FUTURE RESEARCH}

The results indicate that financial managers of state and local governments are aware of their responsibilities for maintaining appropriate internal controls but express only slight interest in, willingness to, or belief they are able to modify internal controls to address the changes in accounting systems as a result of the adoption of e-services. Nevertheless, strong internal controls are imperative when Web-based e-services are offered (Greenstein and Ray 2002). 
Since 1981, generally accepted government auditing standards have required auditors of SLGs to issue written reports on the government's overall internal control and compliance with applicable laws and regulations. Although these reports are not opinions, they provide important information about the entity's control environment. Therefore, financial managers of SLGs should be sensitive to their responsibilities for maintaining internal controls. This sensitivity to internal control responsibilities, however, does not seem to translate into action (intention). The average response of +1 (on a scale of -3 to +3 ) indicates a mild propensity to modify internal control procedures as a result of changes in accounting processes, which may be explained by the environment in which they work. The oversight of most SLGs is provided by elected officials, who may have a tendency to micromanage operations. The ability of financial managers to exercise professional judgment in managing the financial affairs of the SLG can be limited under such conditions.

Results of this study suggest a lack of administrative congruity in SLGs between understanding the need for making appropriate changes to internal controls when business processes are changed and acting on this knowledge. A lack of resources might help explain this phenomenon. Many SLGs are undercapitalized and thus constantly short of funds to support daily operations. The implementation of e-services would most likely be funded from a capital budget, whereas modifications of internal controls would be part of operating costs. Once the capital expenditures are made on the new technology, it may be problematic to obtain additional operating funds to modify internal controls. As long as the technology appears to be working as intended, funds for additional controls in subsequent operating budgets may have a lower priority than other, more recently pressing, issues.

Some units have unstable sources of revenue that vary considerably based on the national or local economy. The failure of elected officials who set policy to understand the importance of effective internal controls may hamper the efforts of financial managers in executing their professional responsibilities. Under these conditions financial managers may have to cut corners when implementing accounting changes such as the adoption of eservices because the resources do not exist to appropriately study and modify the internal control environment.

Nevertheless, additional funding is not required for all internal control changes. Ensuring an adequate separation of incompatible tasks is an important control that would not require significant additional resources. For example, Barings Bank in London discovered (too late) the importance of segregating duties when a Singapore office employee was able to engage in illegal derivatives trades. The employee had authority over both front-office transactions and back-office bookkeeping, resulting in the ultimate failure of the 200-year old financial institution (Davies 2007).

Another control that would not necessitate additional resources is authorization of all software changes. For entities with internal I.T. departments, programmers should not modify software without proper authorization. Furthermore, all program changes should be documented, with the appropriate authorization, to satisfy the auditors at year end. Parker (2007) suggests that the programming code should be designed to randomly select transaction levels so employees cannot anticipate a pre-determined threshold. He argues that a consistent transaction limit for the audit trigger can expose an entity to potential fraud. For example, instead of requiring management approval for transactions exceeding $\$ 1,000$, the software could randomly select a limit (say, between $\$ 900-\$ 1,000$ ). Certainly, limits should be changed on a periodic basis, or employees may simply adjust their behavior to encompass the revised limit.

Organizations that maintain multiple systems, which would include governmental entities that add eservices, run the risk of incurring unauthorized intra-system transactions. Employees may discover they are able to fraudulently execute transactions between systems, similar to accounts receivable "lapping." Independent verification of transactions by another employee should serve as a preventive control, without adding substantial costs.

The internal audit function is both a preventive and a detective control. The knowledge that one's work will be scrutinized by the auditors should be a deterrent to potential fraud. Nevertheless, to be effective, management must act on the recommendations of the internal auditors. In the Barings Bank case, the internal auditors made specific suggestions to separate the roles between the authorization of transactions and recordkeeping of those same 
transactions. These recommendations were never implemented by management (Davies 2007). External auditors provide additional detective controls, yet in many cases the auditors fail to find internal control deficiencies or fraud, as a result of relying too heavily the representations of management. Finally, some electronic internal controls may be easily integrated into the software at installation. Examples include a login sequence to access the system, password protection of confidential information, and setting up levels of database privileges so that only authorized personnel can access information that relates specifically to their position, The agency would be well served to request such controls in the request-for-proposal (RFP) so that the cost could be part of the capital budgeting process.

This study contributes to accounting research by providing empirical evidence to support the constructs of the Theory of Planned Behavior. Each of these constructs (attitude, subjective norm, and perceived behavioral control) reveal a different aspect of the behavior and can serve as a focal point in attempting to make behavioral changes (Ajzen 1991). We predicted that the decision (intention) to modify internal controls did not necessarily follow implementation of electronic services in governmental entities. Our findings support this assertion.

\section{Limitations}

This study is subject to several limitations. First, the data were collected from self-reports, which increases the potential for inflated correlations between the dependent and independent variables due to common method variance, a limitation of the Theory of Planned Behavior (Ajzen 1991). Also, an inherent disadvantage to the questionnaire method of data collection is that the researchers are prevented from learning the respondent's motivation for answering the questions. Because of the multiple-choice nature of the questionnaire, there is a lack of free expression, and the questions may have different meanings to different people.

Second, the data in this study are correlational. The patterns observed are not sufficient to infer that the antecedents have causal influence on the decision to modify internal controls. However, Ajzen (1988) has found support for the causal impact of these components on decisions through his many lab and field experiments of the Theory of Planned Behavior.

Third, the study measured intentions, not actual behavior. However, we promised financial managers their responses would be anonymous, and we did not request any identifying information that would have allowed us to send subsequent requests for information about internal controls. Prior research has shown intentions are highly correlated with actual behavior and, therefore, measuring actual behavior is generally not necessary (Ajzen 1991).

Finally, some people may be offended by the impersonal nature of the form and choose not to respond. This may have an impact on the number of responses received.

\section{Future Research}

It is curious that financial managers appear to understand their professional responsibility for the design and execution of efficient internal controls, but indicate moderate propensity to make those changes after implementation of e-services. Future research might investigate possible political impediments from appointed or elected officials. An alternate methodology, such as in-depth interviews, would be required to capture such qualitative information.

Another extension of the research would be to investigate when participants would modify internal controls. Some may decide to modify controls concurrent with the implementation of e-services, while others may make control changes subsequent to the new technology adoption.

\section{REFERENCES}

1. Ajzen, I. 1985. From intentions to actions: A theory of planned behavior. Springer Series in Social Psychology. New York: Springer-Verlag.

2. _ 1988. Attitudes, Personality and Behavior. Chicago: Dorsey Press. 
3. 1991. The theory of planned behavior. Organizational Behavior and Human Decision Processes. 50: $179-211$.

4. __ and M. Fishbein.1980. Understanding Attitudes and Predicting Social Behavior, Englewood Cliffs, NJ: Prentice-Hall.

5. Ashbaugh-Skaife, H., D. Collins, and W. Kinney, Jr. 2006a. The discovery and consequences of internal control deficiencies prior to SOX-mandated audits. Working paper. University of Wisconsin-Madison, University of Iowa, and University of Texas at Austin.

6. _ 2006b. The effect of internal control deficiencies on firm risk and cost of equity capital. Working paper. University of Wisconsin-Madison, University of Iowa, and University of Texas at Austin.

7. Beneish, M., M. Billings, and L. Hodder. 2006. Internal control weaknesses and information uncertainty. Working paper. Indiana University.

8. Bobek, D., and R. Hatfield. 2003. An investigation of the theory of planned behavior and the role of moral obligation in tax compliance. Behavioral Research in Accounting. 15: 13-38.

9. Bryan, S., and S. Lilien. 2005. Characteristics of firms with material weaknesses in internal control: An assessment of Section 404 of Sarbanes-Oxley. Working paper. Wake Forest University and City University of New York.

10. Davies, R. 2007. Classic Financial and Corporate Scandals. http://www.numa.com/ref/barings/bar03.htm\#13.13 (Accessed July 21, 2007).

11. Freeman, R., C. Shoulders, and G. Allison. 2006. Governmental and Nonprofit Accounting: Theory and Practice. $8^{\text {th }}$ Ed. Upper Saddle River, NJ: Pearson Education, Inc., p. 35.

12. Gauthier, S. 2006. Understanding internal control. Government Finance Review. February: 11-16.

13. Ge, W., and S. McVay. 2005. The disclosure of material weaknesses in internal control after the SarbanesOxley Act. Accounting Horizons. 19 (3): 137-158.

14. Gillett, P.R., and N. Uddin. 2005. CFO intentions of fraudulent financial reporting. Auditing: A Journal of Practice \& Theory. 24 (1): 55-75.

15. Greenstein, M. M., and A. W. Ray. 2002. Holistic, continuous assurance integration: e-business opportunities and challenges. Journal of Information Systems. 16 (Supplement): 1-20.

16. Harrison, D. A., P. P. Mykytyn, Jr., and C. Riemenschneider. 1997. Executive decisions about adoption of information technology in small business: Theory and empirical tests. Information Systems Research. 8 (2): 171-195.

17. Hill, M., L. Mann, and A. J. Wearing. 1996. The effects of attitude, subjective norm and self-efficacy on intention to benchmark: A comparison between managers with experience and no experience in benchmarking. Journal of Organizational Behavior. 17: 313-327.

18. Joppe, M. 2004. http://www.ryerson.ca/ mjoppe/ResearchProcess/StratifiedSampling.htm. (Accessed July 21, 2007).

19. Krishnan, G., and G. Visvanathan. 2005. Reporting internal control deficiencies in the post-Sarbanes-Oxley era: The role of auditors and corporate governance. Working paper. George Mason University.

20. Krueger, N. F. Jr., and A. L. Carsrud. 1993. Entrepreneurial intentions: Applying the theory of planned behavior. Entrepreneurship and Regional Development. 5: 315-330.

21. Lacity, M., and M. Janson. 1994. Understanding qualitative data: A framework of text analysis methods. Journal of Management Information Systems. 11 (2): 137-155.

22. Manstead, A. S. R., and S. A. M. van Eekelen. 1998. Distinguishing between perceived behavioral control and self-efficacy in the domain of academic intentions and behaviors. Journal of Applied Social Psychology. 28: 1375-1392.

23. Parker, D. B. 2007. The dark side of computing: SRI International and the study of computer crime. IEEE Annals of the History of Computing.

24. U.S. Department of Commerce, Economics, and Statistical Administration. Census Bureau. 2002 Census of Governments. Washington, DC: Government Printing Office, May 2004. http://www.census.gov/govs/www/index.html (Accessed July 21, 2007).

25. Wallace, W. A. 2004. A Primer on Internal Controls \& Auditing: Crucial to Government \& the Economy. Alexandria, VA: The Association of Government Accountants, p. 8. 


\section{APPENDIX}

SURVEY

Your response to the survey indicates you understand that this is an anonymous survey. Research at XXXX University that involves human subjects is carried out under the oversight of the Institutional Review Board. Phone: XXXX.

The purpose of this survey is to assess the impact of "e-services" on the internal controls in governmental agencies. The meaning of the term "internal controls" may vary between individuals or among organizations. So that everyone uses the same interpretation for the survey, please read the following definition of internal controls before answering the questions. Internal control is the plan of organization and the methods an entity uses to safeguard assets, provide accurate and reliable information, promote and improve operational efficiency, and encourage adherence to prescribed managerial policies.

\section{INSTRUCTIONS}

Thanks for helping us learn more about the impact of "e-government services" on internal controls. In this survey, sometimes you will use rating scales with seven places. Please put an ' $\mathrm{X}$ ' in the place on the scale that best describes your opinion. Place your marks in the middle of the spaces, not on the boundaries.

For example, if you were asked to rate how GOOD or BAD "the economy in the United States" is on such a scale, and you thought the economy was EXTREMELY GOOD, then you would mark an ' $\mathrm{X}$ ' on the scale as follows:

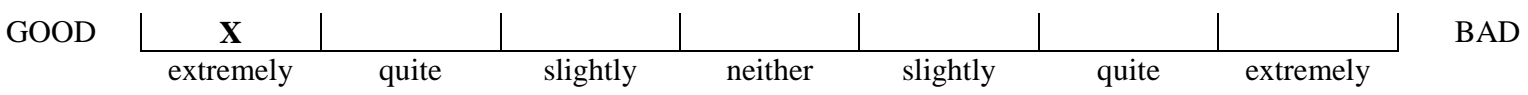

You will also be rating how LIKELY or UNLIKELY something is. You will use the rating scale in the same way. For example, the following rating would indicate you thought improvements to customer service were slightly likely after adding employees:

If our agency adds employees, it is that it will help us improve our service to citizens/taxpayers.

\begin{tabular}{c|c|c|c|c|c|c|} 
UNLIKELY & & & & $\mathbf{X}$ & & \\
LIKELY
\end{tabular}

In making your ratings, please remember to:

1. answer all the items - do not omit any, even if they don't seem to apply to you.

2. never put more than one check mark on a single scale.

\section{E-GOVERNMENT SERVICES and INTERNAL CONTROLS}

Does your governmental organization use electronic transactions (such as e-procurement, e-bids, e-payments) with: [Please check all that apply]

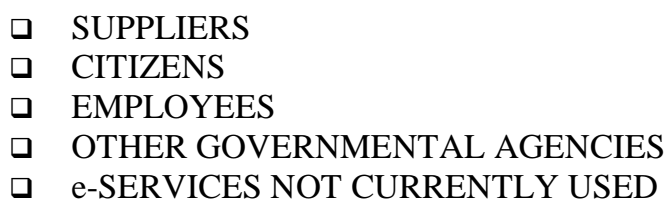

If you marked "e-SERVICES NOT CURRENTLY USED," do plans exist to adopt these services (check one):

a WITHIN 6 MONTHS

a MORE THAN 6 MONTHS BUT LESS THAN 1 YEAR

a MORE THAN 1 YEAR

- NO PLANS AT THIS TIME 
Direct Measure of Behavioral Intention*

\section{YOUR OPINION}

How likely is it that your agency will change internal controls after adoption of e-services?

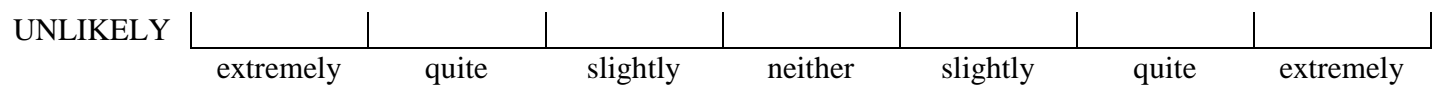

LIKELY

How certain are the plans to change internal controls after e-services adoption?

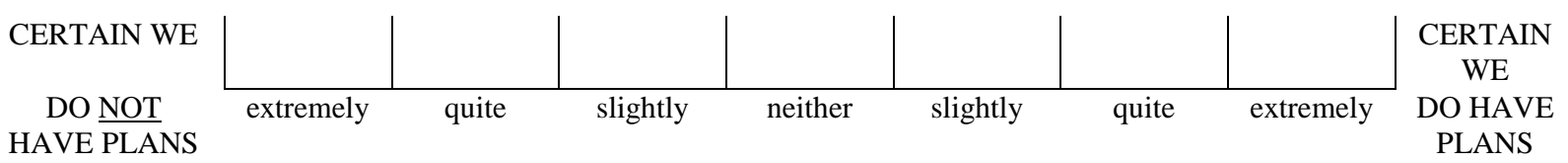

Our agency's commitment to changing internal controls after adoption of e-services is ...

WEAK

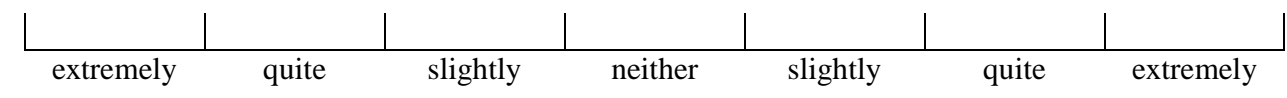

STRONG

Direct Measure of Subjective Norm

How likely is it that most people or groups who are important to your agency would strongly approve of your agency changing internal controls after e-services adoption?

UNLIKELY \begin{tabular}{ll|l|l|l|l|} 
& & & & & LIKELY \\
extremely & quite & slightly & neither slightly & quite extremely
\end{tabular}

Most people or groups who are important to your agency would of changing controls.

DISAPPROVE

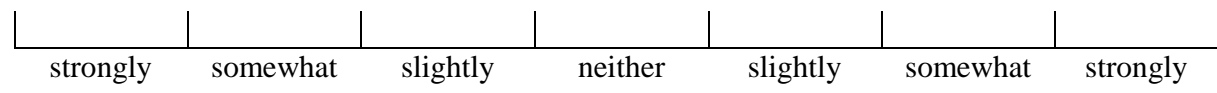

Direct Measure of Perceived Behavioral Control

To your agency, modifying internal controls after e-services adoption would be...

(Please mark each of the following three scales.)
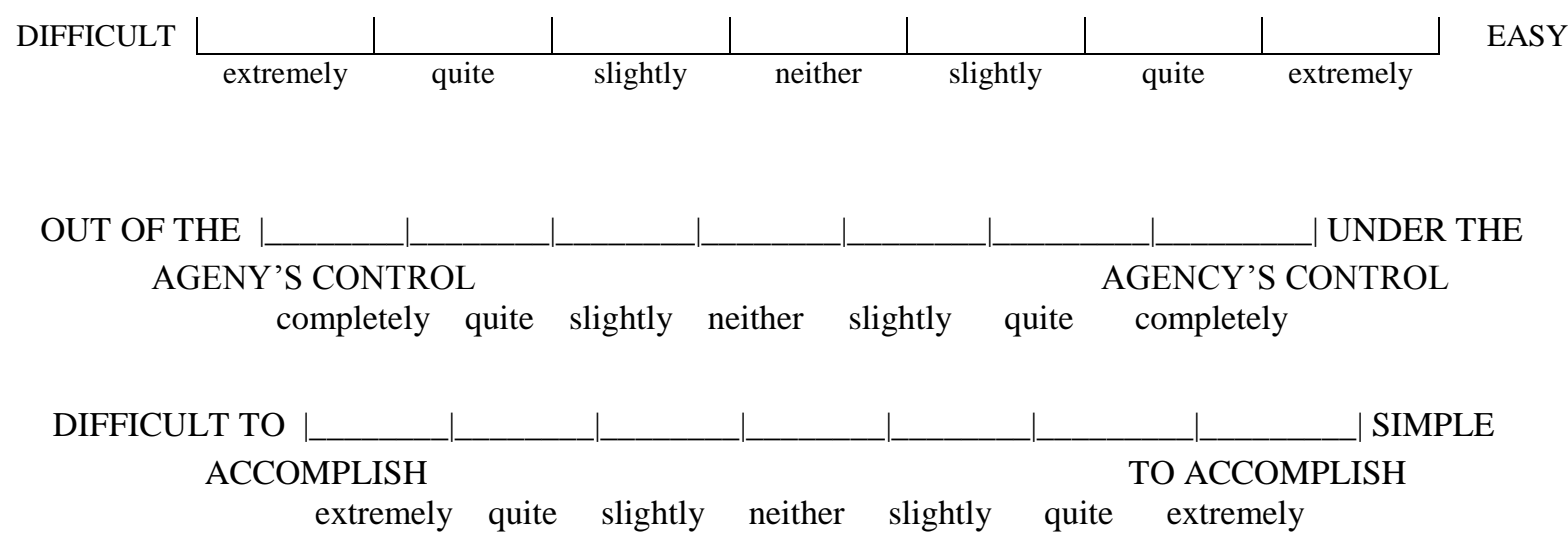

* Labels that signify measurement items were not included in the original survey; they are added for the reader's benefit. 


\section{Direct Measure of Attitude}

It would be ___ for your agency to modify its internal controls after adoption of e-services. (Please mark each of the following four scales.)

BAD

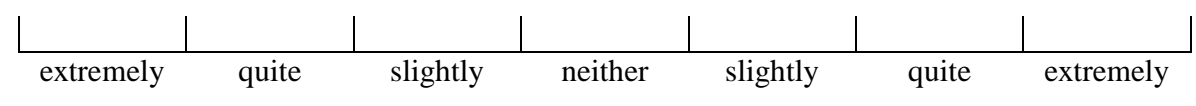

GOOD

HARMFUL

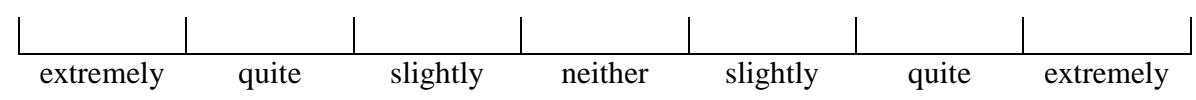

HELPFUL

NEGATIVE

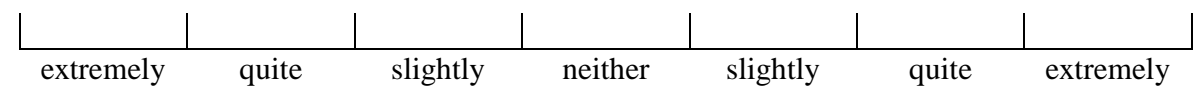

POSITIVE

FOOLISH

\begin{tabular}{|l|l|l|l|l|l|} 
& & & & & \\
\hline extremely & & & & & \\
\end{tabular}

WISE

\section{Measurement Items for Normative Beliefs}

\section{SOCIAL FACTORS}

How much would each of the following people or groups DISAPPROVE or APPROVE of your agency changing internal controls? (Mark each scale so that it completes the statement in a way that best expresses your opinion.)

employees would

DISAPPROVE

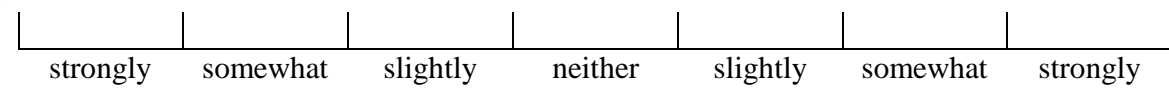

APPROVE

accountants or

auditors would

DISAPPROVE

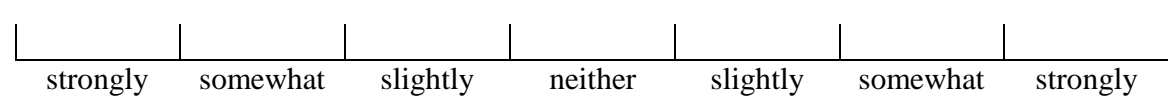

APPROVE

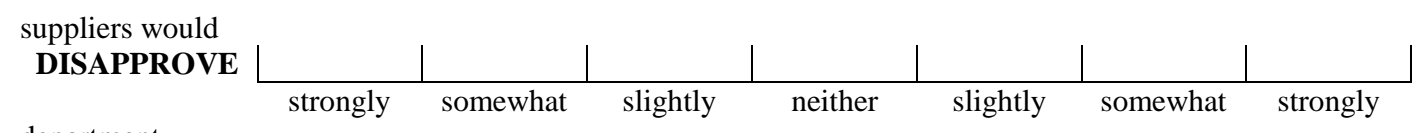

APPROVE

department

managers would

DISAPPROVE

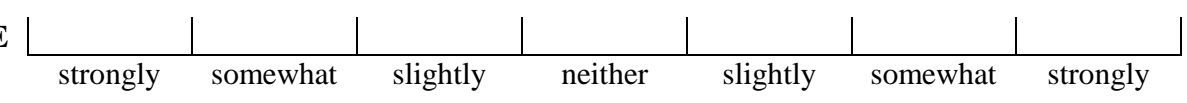

APPROVE

Please put an " $X$ " in a space that indicates, IN GENERAL, how much your AGENCY WANTS to do what the following groups or individuals think it should do. Mark one " $\mathrm{X}$ " per question. For example, if your agency always wants to do what suppliers think it should, you'd mark the "Very Much" part of the scale. If a question does Not Apply, write "NA" next to it. 
IN GENERAL, how much does your agency usually want to do what ...

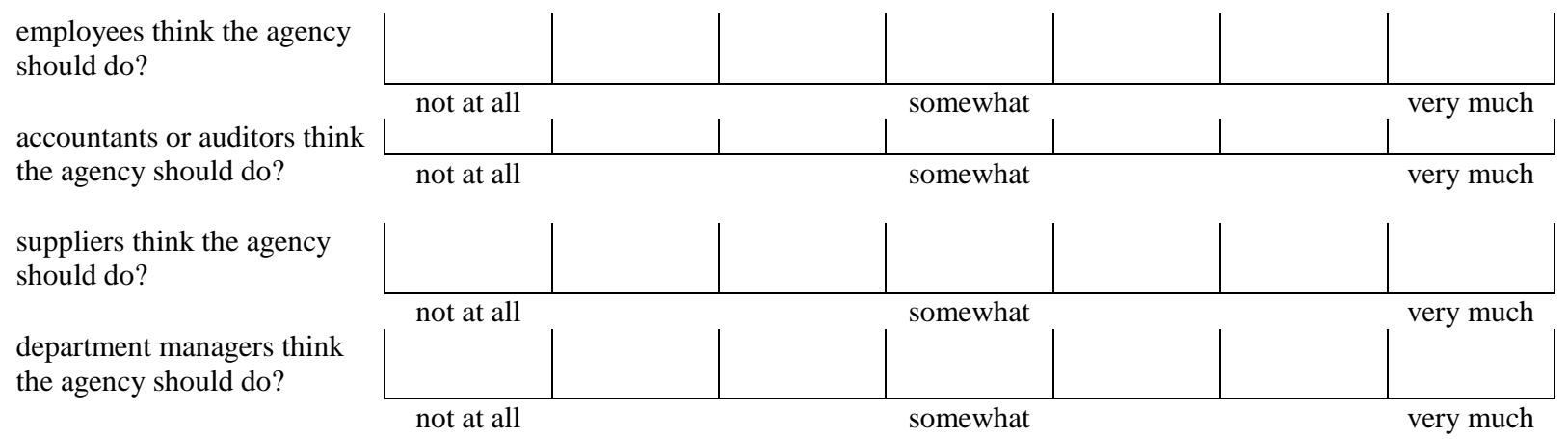

\section{Measurement Items for Control Beliefs}

\section{POSSIBLE OBSTACLES AND BARRIERS}

How likely is it that each of the following factors would keep you from changing internal controls after eservices adoption? (Mark the scale so that it best expresses your opinion.)

budget limitations
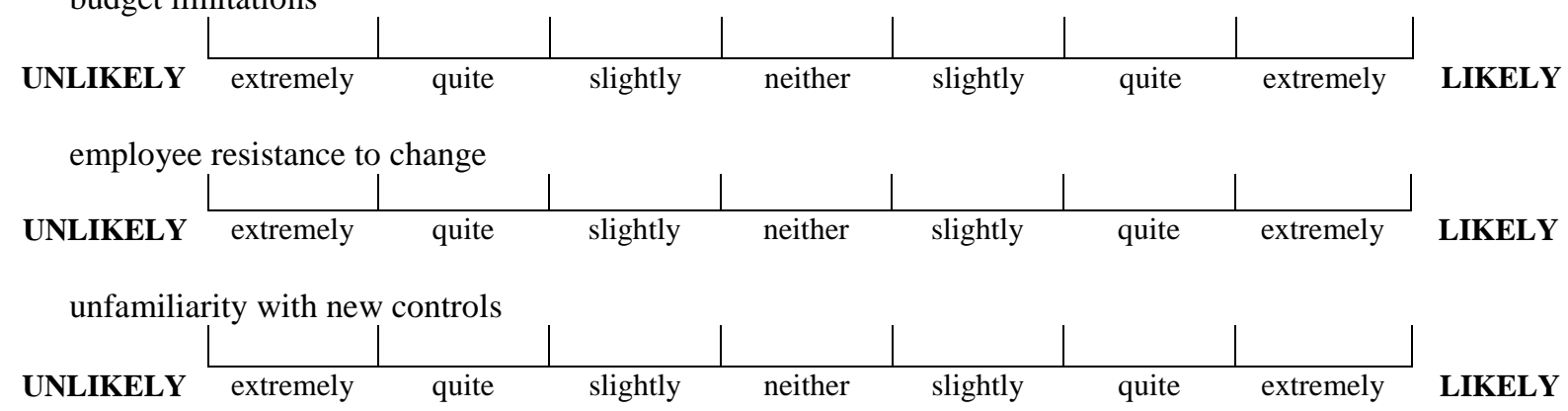

sufficient time to implement new controls

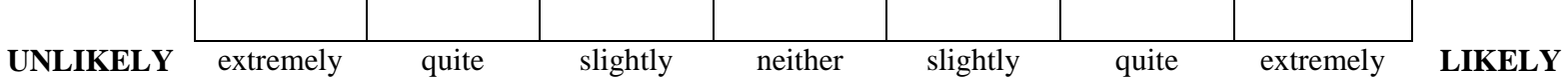

additional training for employees

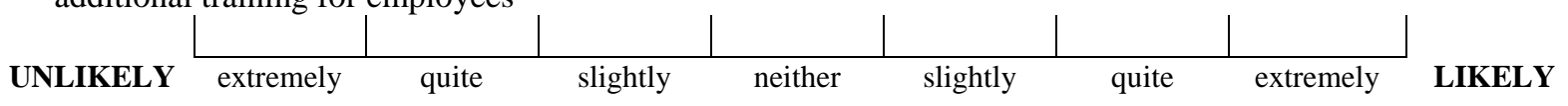

How IMPORTANT is each of the following factors in overcoming barriers to changing controls after adoption of e-services? (Mark the scale so that it best expresses your opinion.)
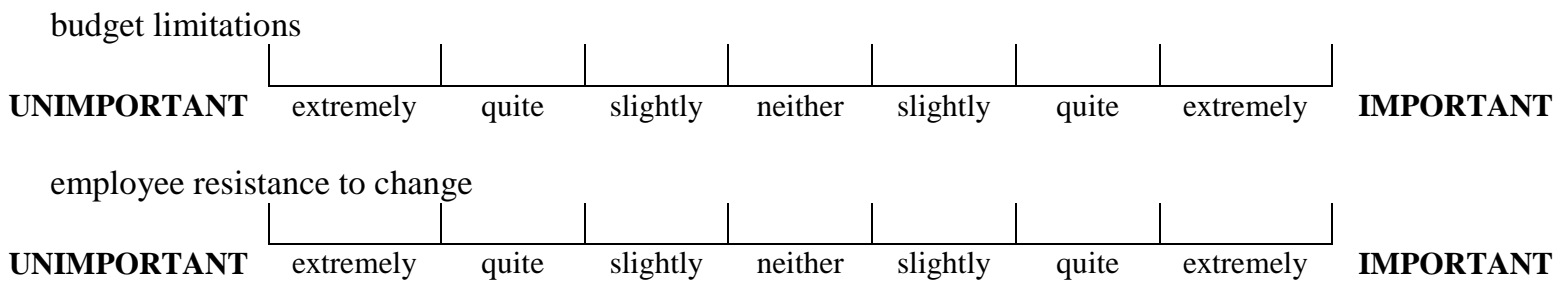

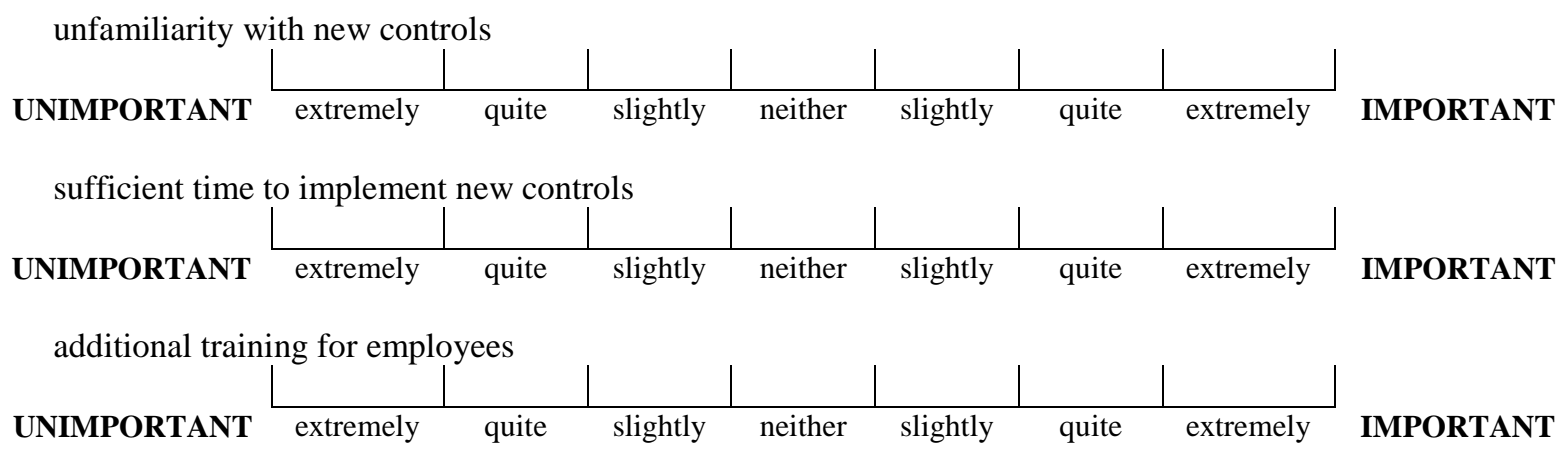

\section{Measurement Items for Behavioral Beliefs}

\section{FUTURE CONSEQUENCES}

The items listed below have to do with the possible consequences you might associate with changing internal controls after adoption of e-services. These have been suggested by other financial directors like you. Mark each scale so that it completes the statement in a way that best expresses your opinion.

If changes are made to the internal controls after e-services adoption, it is ...

UNLIKELY

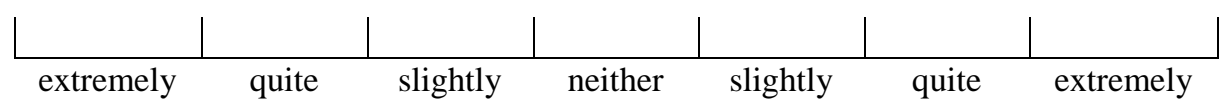

LIKELY

that it will enhance the accuracy of the accounting records.

UNLIKELY

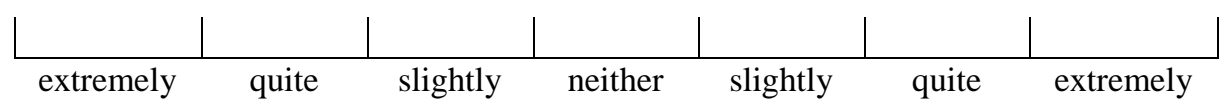

LIKELY

that daily operations will be more efficient.

UNLIKELY

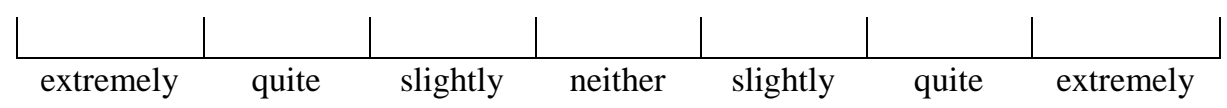

LIKELY

that it will decrease fraud or errors.

UNLIKELY

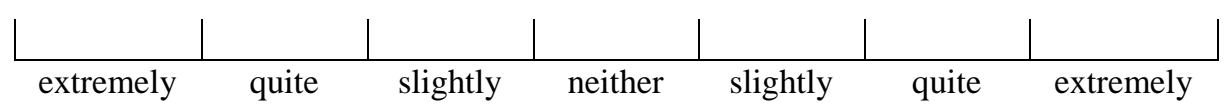

LIKELY

that accounting costs will be reduced.

UNLIKELY

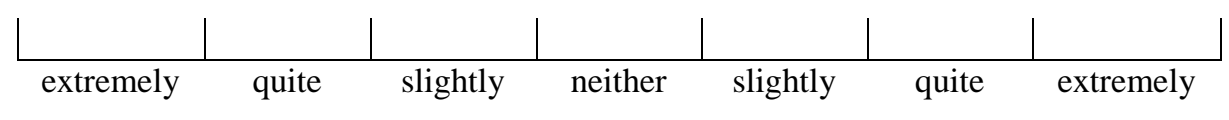

LIKELY

that fewer personnel will be required.

UNLIKELY

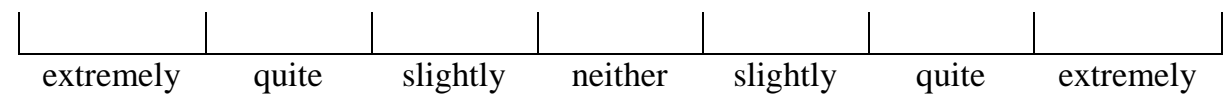

LIKELY

that it will make the agency's financial information more reliable. 


\section{ASSESSMENT}

In the previous section, you gave your opinion on how likely specific consequences would occur if the agency changed internal controls after implementing e-services. Now, please mark each scale that best expresses how positive (good) or negative (bad) you feel about those future consequences, in general.

accuracy of the accounting records

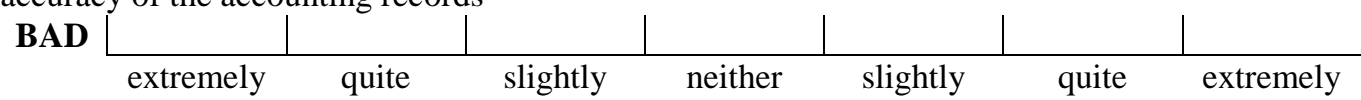

GOOD

more efficient daily operations

BAD \begin{tabular}{l|l|l|l|l|} 
& & & & \\
extremely quite slightly neither slightly quite extremely
\end{tabular}

GOOD

decreased fraud or errors

\begin{tabular}{l|l|l|l|l|} 
BAD $\bigsqcup_{\text {extremely quite }}$ & & & & \\
reduced accounting costs & slightly neither slightly & quite extremely
\end{tabular}

GOOD

BAD \begin{tabular}{l|l|l|l|l|l|} 
& & & & & \\
\hline extremely quite slightly neither slightly quite extremely
\end{tabular}

GOOD

fewer personnel required

\begin{tabular}{|l|l|l|l|l|} 
BAD & & & & \\
\hline extremely quite slightly neither slightly & quite extremely
\end{tabular}

GOOD

more reliable financial information for the agency

BAD

\begin{tabular}{|l|l|l|l|l|l|} 
& & & & & \\
\hline extremely & quite slightly neither slightly quite extremely
\end{tabular}

GOOD

\section{$\underline{\text { Demographics }}$}

A little information about you -- please complete the following section for STATISTICAL PURPOSES ONLY.

Prior to receiving this survey, how often have you thought of changing internal controls after e-services adoption?

Please enter a number between 1 and 5 , with $1=$ NEVER and $5=$ FREQUENTLY.

Prior to receiving this survey, how many (approximately) internal control changes already had been made?

Please enter a percentage $(0 \%-100 \%)$, with $0 \%=$ NONE and $100 \%=$ ALL PLANNED CHANGES

How much does the decision to modify internal controls depend on your personal opinion?

Please enter a percentage $(0 \%-100 \%)$ 


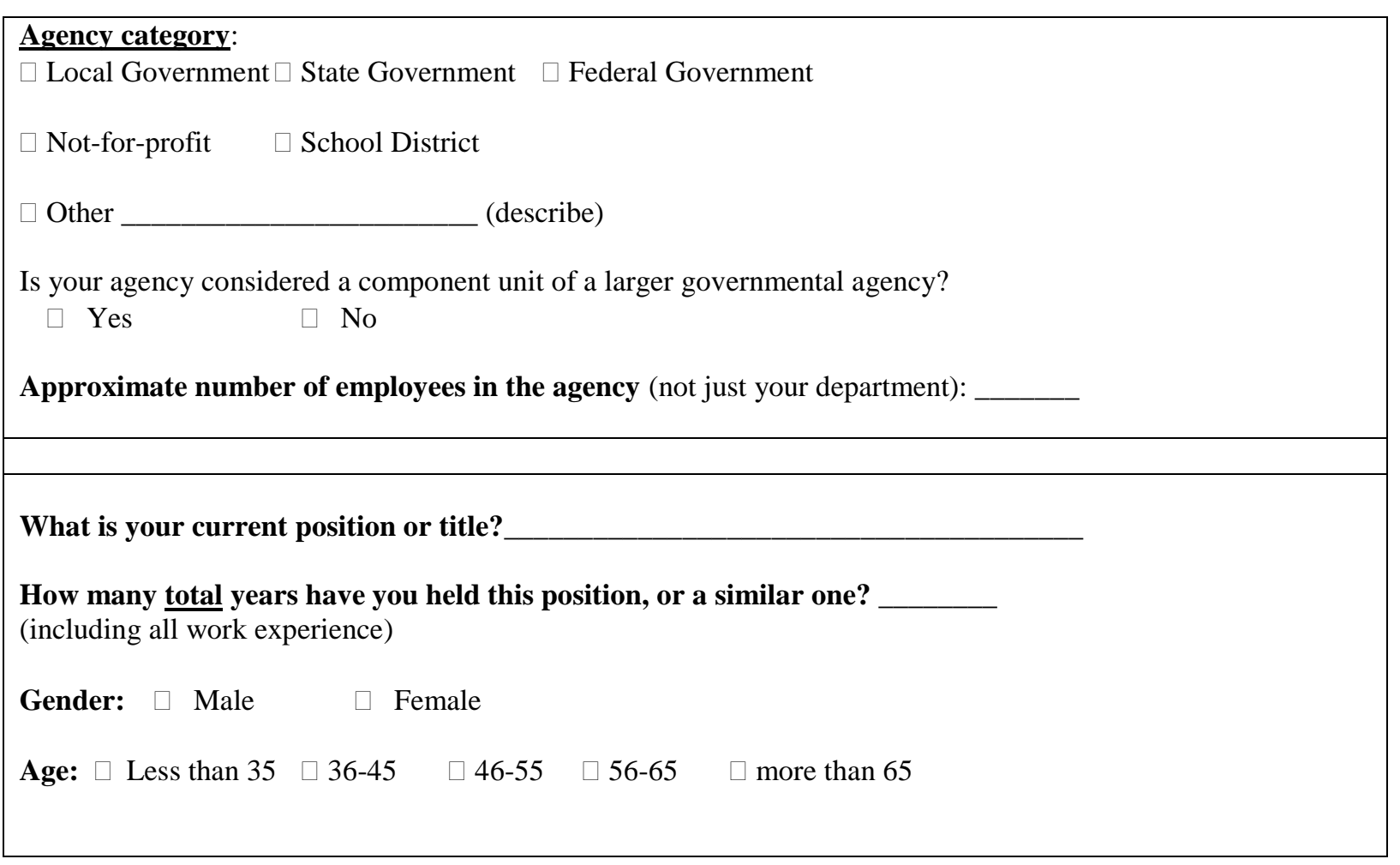

NOTES 